\title{
Efficacy of Rituximab on Rheumatoid Leptomeningitis as the First Symptom of Rheumatoid Arthritis
}

\author{
Mickaël Chouk ${ }^{1}$, Alexandre Halb² ${ }^{2}$, Christine Mekhail ${ }^{1}$, Amélie Godot $^{3}$, Frank Verhoeven ${ }^{1}$, Clément Prati $^{1}$, Daniel Wendling ${ }^{1}$ \\ ${ }^{1}$ Service de Rhumatologie, CHRU Besançon, Besançon, France \\ ${ }^{2}$ Service de Neurologie, CHRU Besançon, Besançon, France \\ ${ }^{3}$ Service de Médecine Interne, CHRU Besançon, Besançon, France
}

Received: 04/02/2021

Accepted: 01/04/2021

Published: $21 / 04 / 2021$

How to cite this article: Chouk M, Halb A, Mekhail C, Godot A, Verhoeven F, Prati C, Wendling D. Efficacy of rituximab on rheumatoid leptomeningitis as the first symptom of rheumatoid arthritis. EJCRIM 2021;8: doi:10.12890/2021_002358.

Conflicts of Interests: The Authors declare that there are no competing interests.

This article is licensed under a Commons Attribution Non-Commercial 4.0 License

\section{ABSTRACT}

Rheumatoid arthritis (RA) is a chronic inflammatory disease characterized mainly by arthritis, with the possible occurrence of extra-articular manifestations. We report the case of a patient who developed leptomeningitis as the first sign of RA, one year before the diagnosis of RA. Methylprednisolone $1000 \mathrm{mg}$ was given intravenously. Because of the onset of seizures and cognitive impairment, rituximab was started. After three cycles of rituximab (1000 mg on day 0 and $1000 \mathrm{mg}$ on day 15, every 6 months), neurological clinical examination, MRI and electroencephalogram findings were significantly improved.

\section{LEARNING POINTS}

- Rheumatoid meningitis may occur in the disease course of rheumatoid arthritis with varied and non-specific symptoms.

- Cerebrospinal fluid examination, MRI and tests for rheumatoid factor or anti-citrullinated protein antibodies in serum or in cerebrospinal fluid are key examinations for diagnosing rheumatoid meningitis.

- Rituximab has good efficacy in rheumatoid meningitis.

\section{KEYWORDS}

Rheumatoid arthritis, rheumatoid meningitis, rituximab, leptomeningitis, seizure

\section{INTRODUCTION}

Rheumatoid arthritis (RA) is a chronic inflammatory disease affecting the joints, although symptomatic involvement of other organs may also occur. Neurological disorders are rare, while extra-articular involvement is even more uncommon as the initial symptom presentation of RA. We report the case of a patient who presented leptomeningitis as the initial symptom, one year before the diagnosis of RA was made.

\section{CASE PRESENTATION}

A 62-year-old woman was seen in the neurology department in February 2018 for sudden numbness of the proximal upper right limb. She had a medical history of acute rheumatic fever in childhood, and a 30-year history of high blood pressure. Of note, cerebral MRI performed in June 2017 to investigate vertigo was normal.

Table 1 details the symptoms, laboratory examinations, radiology examinations, and clinical evaluation/medical decision-making during follow-up. 
Rheumatoid leptomeningitis was diagnosed in February 2019, 1 year after the first neurological symptom. This diagnosis made it possible to avoid cerebral biopsy.

In April 2019, after steroid therapy with 1000 mg of methylprednisolone for 3 days, the patient suffered seizure and cognitive impairments, including instrumental disorders (visuospatial, language and praxis), as well as executive difficulties and working memory disorders. We therefore decided to prescribe a cycle of rituximab (1000 mg on day 0 and $1000 \mathrm{mg}$ on day 15).

In October 2019, the neurological conditions and electroencephalogram findings had significantly improved: the dose of lacosamide was therefore decreased, and no new seizures ensued. Cognitive function also significantly improved. A fourth MRI was performed, and showed complete regression of signs of meningitis (Fig. 1). There were no swollen or tender joints. We decided to prescribe a second cycle of rituximab.

In April 2020, the neurological examination findings were further improved, and the patient remained free of rheumatic symptoms. We decided to prescribe a third cycle of rituximab.

In October 2020, neurological and rheumatic conditions were comparable to those in April 2020, and rituximab was discontinued.
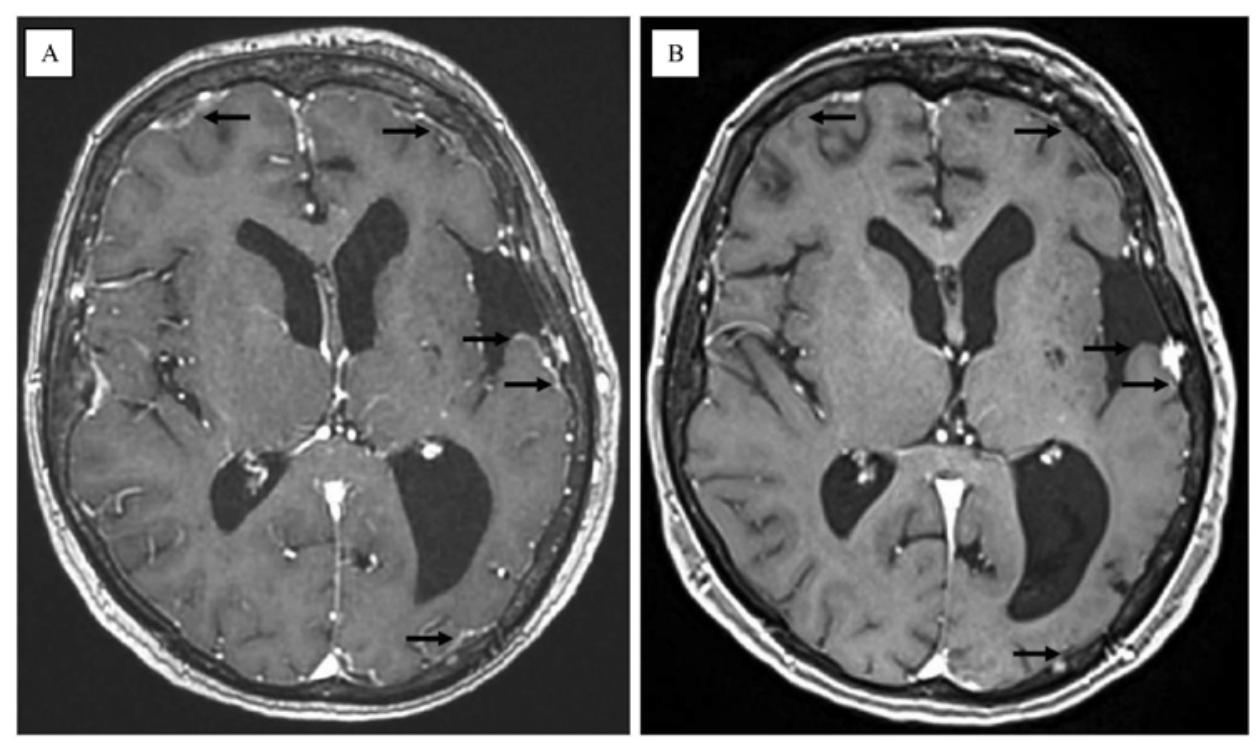

Figure 1 MRI. (A) December 2018, post-contrast enhancement in the leptomeninges on T1-gadolinium sequence (black arrows). (B) October 2019, complete regression of post-contrast enhancement in the leptomeninges on T1-gadolinium sequence (black arrows)

\section{DISCUSSION}

Our case illustrates the development of rheumatoid (lepto)meningitis (RM) preceding the diagnosis of RA, and the efficacy of rituximab on RM.

Although neurological disorders in RA patients are rare, the peripheral nervous system is mostly involved, with peripheral neuropathy, while central nervous system involvement affects the meninges in particular ${ }^{[1]}$.

$\mathrm{RM}$ is rare, but has previously been described in the literature ${ }^{[2,3]}$. RM patients are generally aged between 60 and 65 years, and more than $50 \%$ of them have been followed for RA for less than 10 years. Focal weakness, headache, seizures, psychiatric symptoms, rheumatoid meningitis stroke-like attacks, and confusion are the most frequent symptoms of RM. Initially, symptoms are episodic but become more persistent as the disease course progresses. Rheumatoid factor (RF) and anti-citrullinated protein antibodies (ACPA) are positive in the serum of almost all patients, often at high levels. In the cerebrospinal fluid (CSF), white blood cells $>15 / \mathrm{mm}^{3}$, with lymphocyte predominance, and protein $>0.45 \mathrm{~g} / \mathrm{l}$ are frequent. Gadolinium-MRI shows post-contrast enhancement of the leptomeninges, frequently bilaterally distributed, and of the superior pole of the frontoparietal lobes of the brain in the sagittal plane. In more than $90 \%$ of cases, cerebral biopsy is performed to confirm the diagnosis. In more than $80 \%$ of cases, intravenous steroid therapy is started. A conventional synthetic disease-modifying antirheumatic drug (DMARD), such as methotrexate or cyclophosphamide, is started in 40\% of cases. If a biologic DMARD is required, rituximab should be preferred, because it has been prescribed in 12 cases reported in the literature (and as such, is the most widely used), while anti-TNFa may be less effective. 


\begin{tabular}{|c|c|c|c|c|}
\hline $\begin{array}{l}\text { Date } \\
\text { (month/year) }\end{array}$ & Symptoms & Laboratory examinations* & Radiology examinations & Clinical evaluation \\
\hline $02 / 2018$ & $\begin{array}{l}\text { Sudden numbness of } \\
\text { the proximal upper right } \\
\text { limb }\end{array}$ & None & $\frac{C T \text { scan: }}{\text { frontal right meningioma }}$ & None \\
\hline $10 / 2018$ & $\begin{array}{l}\text { Partial seizure } \\
\text { secondarily generalized }\end{array}$ & None & None & $\begin{array}{l}\text { Seizure } \\
\text { Start lacosamide }\end{array}$ \\
\hline $12 / 2018$ & $\begin{array}{l}\text { New episodes of } \\
\text { abnormal movements } \\
\text { Daily headache } \\
\text { Problems with touch } \\
\text { sensitivity and language }\end{array}$ & $\begin{array}{l}\text { Blood: } \\
\text { Extensive serological tests ruled out the most likely } \\
\text { viral and bacterial infections. } \\
\text { Anti-nuclear, anti-DNA, anti-neutrophil cytoplasmic, } \\
\text { anti-cardiolipin, anti- } \beta 2 \mathrm{GPI} \text {, anti-neuronal nuclear } \\
\text { antibodies: negative } \\
\frac{\mathrm{CSF} \text { : }}{20 \text { white blood cells } / \mathrm{mm}^{3}, \text { protein } 0.51 \mathrm{~g} / \mathrm{l},} \\
\text { no oligoclonal profile, no pathogenic germs } \\
\text { Minor salivary gland biopsy: } \\
\text { normal }\end{array}$ & $\begin{array}{l}\text { MRI: } \\
\text { supra-tentorial thickening } \\
\text { of leptomeninges in } \\
\text { hypersignal on T2 FLAIR } \\
\text { and diffusion sequences and } \\
\text { post-contrast enhancement } \\
\text { in leptomeninges } \\
\text { FDG-PET/CT: } \\
\text { normal }\end{array}$ & $\begin{array}{l}\text { Leptomeningitis } \\
\text { Increase lacosamide }\end{array}$ \\
\hline 01/2019 & New episodes of seizure & None & $\begin{array}{l}\text { MRI: } \\
\text { antibody encephalitis } \\
\text { (Fig. 1) }\end{array}$ & $\begin{array}{l}\text { MRI suggestive of } \\
\text { granulomatous pathology } \\
\text { or inflammatory antibody } \\
\text { reaction } \\
\text { Increase lacosamide and } \\
\text { start levetiracetam }\end{array}$ \\
\hline 02/2019 & & $\begin{array}{l}\text { Blood: } \\
\text { RF } 90 \text { IU } / \mathrm{ml}, \text { ACPA }>340 \mathrm{IU} / \mathrm{ml} \\
\text { Genotype HLA-DRB1*01 } \\
\text { CSF: } \\
\text { ACPA } 76 \mathrm{IU} / \mathrm{ml} \\
\text { Large granular lymphocytes on flow cytometry } \\
\text { High concentration of IL-6 with IL-10/IL-6 ratio }<1 \\
\text { Biopsy of the flexor tenosynovitis: } \\
\text { compatible with RA }\end{array}$ & $\begin{array}{l}\text { Hand } x \text {-ray and ultrasound } \\
\text { scan: normal } \\
\text { (except tenosynovitis) }\end{array}$ & $\begin{array}{l}\text { Rheumatoid } \\
\text { leptomeningitis }\end{array}$ \\
\hline
\end{tabular}

Table 1. Patient symptoms, findings and evaluation

${ }^{*}$ Routine laboratory examinations are not reported.

ACPA, anti-citrullinated protein antibodies; CSF, cerebrospinal fluid; IL, interleukin; RA, rheumatoid arthritis; RF, rheumatoid factors.

RM in patient with RA already treated by an anti-TNFa has previously been reported ${ }^{[3]}$. It is noteworthy that cases of progressive multifocal leukoencephalopathy due to polyomavirus JC in patients treated by rituximab have been reported, but no RM ${ }^{[4]}$. Data on tocilizumab are very scarce.

Although some features of our RM case are consistent with the literature, there are also some novel aspects. First, in the literature, only 10 patients who developed RM before RA have been reported ${ }^{[2,3]}$, rendering our case original and relatively rare. Second, to the best of our knowledge, although ACPA are present in the serum of almost all RM patients, ACPA in the CSF has not previously been reported. Third, a further original feature is the investigation of the patient's genotype. It is well known that the HLA-DRB1*01 genotype is associated with the development and severity of RA. Nevertheless, there is no known impact of HLA-DRB1 genes on extra-articular disease manifestations in $\mathrm{RA}^{[5]}$. More specifically, there is no evidence in the literature supporting a relationship between HLA-DRB1*01, RA and RM. Fourth, a cerebral biopsy is performed in almost all cases, but the diagnostic importance of synovial biopsy, as in our case, is reported here for the first time. Fifth, thanks to these novel aspects and the collaboration between rheumatologists and neurologists, we were able to avoid a risky cerebral biopsy. Lastly, the efficacy of rituximab has rarely been reported in the literature (12 cases only). 
In conclusion, rheumatologists should be aware of neurological manifestations in RA patients, because, although rare, peripheral or central nervous system involvement in RA is possible with a large variety of symptoms. Furthermore, neurologists should suspect RA in case of leptomeningitis, because, although rare, it can be effectively treated with bDMARDs used in RA, such as rituximab. Collaboration between neurologists and rheumatologists appears to be essential.

Five points that could help the medical community recognize RM in advance in case of leptomeningitis, with the aim of treating it properly, are the following:

1. Pay attention to bilateral post-contrast enhancement in the leptomeninges in the superior pole of the frontoparietal lobes in the sagittal plane on gadolinium-MRI,

2. Track any rheumatic symptoms, even if minor,

3. Check for RF and ACPA in the serum and ACPA in the CSF,

4. Identify Major Histocompatibility Complex class II genes,

5. Conduct a synovial biopsy, which is safe, rather than a cerebral biopsy.

\section{REFERENCES}

1. Joaquim AF, Appenzeller S. Neuropsychiatric manifestations in rheumatoid arthritis. Autoimmun Rev 2015;14(12):1116-1122.

2. Rodriguez Alvarez M, Rodríguez Valencia LM, Seidman R, Acharya A, Espina N, Ravindran N, et al. Rheumatoid meningitis and infection in absence of rheumatoid arthritis history: review of 31 cases. Clin Rheumatol 2020;39(12):3833-3845.

3. Qin Z, Kim J, Valencia D, Hamoodi L, Neltner J, Sizemore T, et al. Rheumatoid meningitis: a case report and review of the literature. Neurol Clin Pract 2020;10(1):73-83.

4. Atzeni F, Talotta R, Masala IF, Gerardi MC, Casale R, Sarzi-Puttini P. Central nervous system involvement in rheumatoid arthritis patients and the potential implications of using biological agents. Best Pract Res Clin Rheumatol 2018;32(4):500-510.

5. Turesson C, Schaid DJ, Weyand CM, Jacobsson LTH, Goronzy JJ, Petersson IF, et al. The impact of HLA-DRB1 genes on extra-articular disease manifestations in rheumatoid arthritis. Arthritis Res Ther 2005;7(6):R1386-R1393. 